\title{
Issues that Have Affected Quality Assurance in the Albanian Higher Education System between 1992-2012
}

\author{
Mimoza Karagjozi- Kore \\ Faculty of History and Phylology, University of Tirana, Albania \\ mimo.kore@gmail.com
}

\section{Doi:10.5901/ajis.2013.v2n2p113}

\begin{abstract}
Academic staff, students and other members of society concerned about education have continuously argued the quality of institutions providing higher education in Albania. This research deals with an in-depth analysis of issues concerning Albanian universities. These issues are compared and contrasted between two different time spans; 1992-2003 and 2003-2012. A cross case analysis is used to examine several factors that affect the quality of universities such as: the criteria used to design an academic course, the qualification of academic staff, the quality of students accepted and the infrastructure of the buildings. Conclusions are encouraging as they illustrate that society is highly interested in improving the quality of universities. The increasing number of enrolled students, the high competition between universities and the constant discussion of quality issue by media and respective government authorities have all served as a catalyst for favorable change.
\end{abstract}

Keywords: academic staff, Bologna process, course designing, course curricula, quality in higher education, quality issues in universities.

\section{Introduction}

Education is not only a common benefit to the society but a big responsibility to deliver quality. For universities to be able to produce and transmit knowledge, scientific information and evolve their research practices, they should firstly have a long experience and should provide reliability to the society and the overall job market. To achieve this purpose, universities should have intellectual freedom regarding teaching and research practices as well as the assertion to provide high quality services to students. Academic quality is recently a worldwide issue which sets the bar between institutions of higher education in times of intense competition (Yarmohammadin, Mozaffary, Esfahani, 2011). There has been an increase in the concern of how universities deliver quality services, because it is directly correlated to public as well as private expanses. The purpose of this study is to elaborate on how the concept of quality in higher education in Albania has changed over the years. To illustrate the changes, evidence will come from factors which improve quality as well as those that impede it. This research would serve as a source of information to the academic staffs, students and Albanian government authorities who consider quality. To a certain extent it will also help to understand how able the Albanian higher education system is to fulfill the European standards of quality which are a desired target for all participants of the system. Due to the fact that there is a limited number Albanian publications regarding the topic, this study will be based on information provided by the Albanian Ministry of Science and Education as well as non-Albanian articles focusing on academic quality.

\section{Literature Review}

There is currently a need to define quality and then move along to evaluate whether Bologna Process helped to improve it or not (Kohont, Bergoc, 2010). The conclusions of previously published works, define quality as a subjective concept which can be interpreted in several ways. As Mishra (2007) claims, quality is a very relative concept especially compared through different time periods. Kohont and Bergoc (2010) highlight the changes in what determines quality. Quality undergoes changes during the years but it is still considered a difficult concept to apply and measure. Achieving quality requires a constant effort in time to maintain and improve the overall condition. As Tsinidou, Gerogiannis and Fitsilis (2010) argue, quality is very complex depending on different point of views that stakeholders have regarding it. 
Pratasavitskaya and Stensaker (2012) regard quality as an externally driven process which can be affected by the degree of accountability that the society requires from the higher education system. The study of Pratasavitskaya and Stensaker (2012) categorizes issues that impede quality improvements in a similar manner with this research and serves as a supportive pillar. Past studies have mainly focused on national or institutional levels of discussing quality. Frank, Kurth and Mironowicz (2012) suggest that the study of quality should be studied more narrowly especially when a degree is directly connected to the

In post-communist, Eastern European countries like Albania, quality is tightly connected to the academic inheritance of the past regime and needs to undergo several changes to be fully integrated into the European academic environment. However, Albania was not a sole isolated case. As Zgaga (2009) alleges, all ex socialist eastern European countries faced several problems.

The first steps of higher education in Albania go back to 1946 when the 2-year Pedagogic Institution of Tirana was opened. The first university in Albania was Tirana University, created in 1957 (Woodard, 2005). It relied on the experience of the previous institutions existing at the time like: The Pedagogic Institution, Polytechnic Institution, Economic Institution, Medical Institution, Legal Institution and Science Institution.

Until the 90's, the academic system in all its levels was based on the Russian model. The democratic developments that followed, created a need for the reorganization of the whole system. Several issues and challenges were faced during this reorganization period because of the absence of a model to follow and a grounded plan on which the whole reorganization process could be based. The issues, problems and characteristics experienced are reflected into the developments that make up the two selected time periods, 1992-2003 and 2003-2012.

\section{Research Methodology}

The research uses as a cross case analysis between two different time periods, 1991-2003 and 2003-2012 respectively. The division into these times periods is made due to a few important reasons. During 1991-2003, universities in Albania tended to copy every practice coming from foreign universities. This period is regarded as a phase of academic confusion. The second time period, 2003-2012, initiated with the signing of Bologna Process which brought discipline into the higher education system. "Bologna reform is the process of creating the European higher education area (EHEA)" (Kohont, Bergoc, 2010). Bologna reform brought with itself a set of criteria and standards to be followed and fulfilled.

The cross case analysis would be based on three essential events that happened during the two selected time period.

\subsection{1st Period: 1991-2003}

1. These years are characterized by movements of academic staff to foreign universities with the purpose of exchanging experiences. This process was facilitated by different projects one of which was "Tempus". Through these projects, academics had the chance to share and gain new experiences in their fields of study. This brought a confrontation of where Albanian universities were standing with regards to other European universities. During this time commination links were established not only between universities but between professors, students and their counterparts in European universities. Even though this period was beneficial for the Albanian system of higher education, it created a major drawback. Academics in a rush to gain what Albanian education was lacking for years, started to translate foreign textbooks to their students instead of creating a suitable model for Albania. Another problem as Woodard (2005) regards it was that "the university system has suffered from both internal and external brain drain". This meant that many academic that went abroad to gain experience, tried to establish themselves there and did not return back to Albania.

2. During the communist times, universities were attended by only top students who had the highest grades in their previous studies. After communist regime fell, many factories and industrial plants were destroyed. Young people working in them headed back into universities which created massive waves of university attendance. Previously universities were located in Tirana and a few other towns which provided specific advantages. However, now new universities were created in many other towns to accommodate the raising demand of students.

3. In 2002 the first private university was created, as an alternative to the public one (APAAL, n.d.). 
1. This period is characterized by several reforms which mainly involved improving the quality of higher education. The first time when the subject of quality was brought up was after the assignment of Bologna Reform in 18th of September 2003 in Berlin (APAAL, 2007). According to this reform, the system of higher education would change based on a set of standards which were accepted and applied by all European countries. This could make the system of higher education comparable and compatible to more advanced existing European systems. Bologna Process brought about a few requirements like: assuring and measuring quality, reorganization of courses and curricula, creation of a transferable credit system, recognition of degrees and the development of a new legislation which would serve as a backbone to the whole process. The changes initiated by the Bologna Process created a new environment and removed the general apathy that was prevailing in the overall academic system. This process conceived the path on which the strategies for quality improvement would rely in the future. Everyone involved in the higher education system was conscious of the need that existed to implement these changes. A unified policy for all higher education institutions was a necessity regardless the continuous efforts during the years, changes in departmental structures, course designs, teaching process, scientific research methods, infrastructure, etc. Quality was still far behind contemporary European levels.

2. Another major contribution during this period was the creation of the Accreditation Agency for Higher Education which immediately started to work on composing and spreading among universities the unified standards of measuring quality. This institution comes under the Ministry of Science and Education. By not being an independent entity, the reliability of the agency consequently decreases. So far the agency has provided accreditation to several public universities and all private ones. Figure 1 illustrates the accreditation process from 2002-2012.

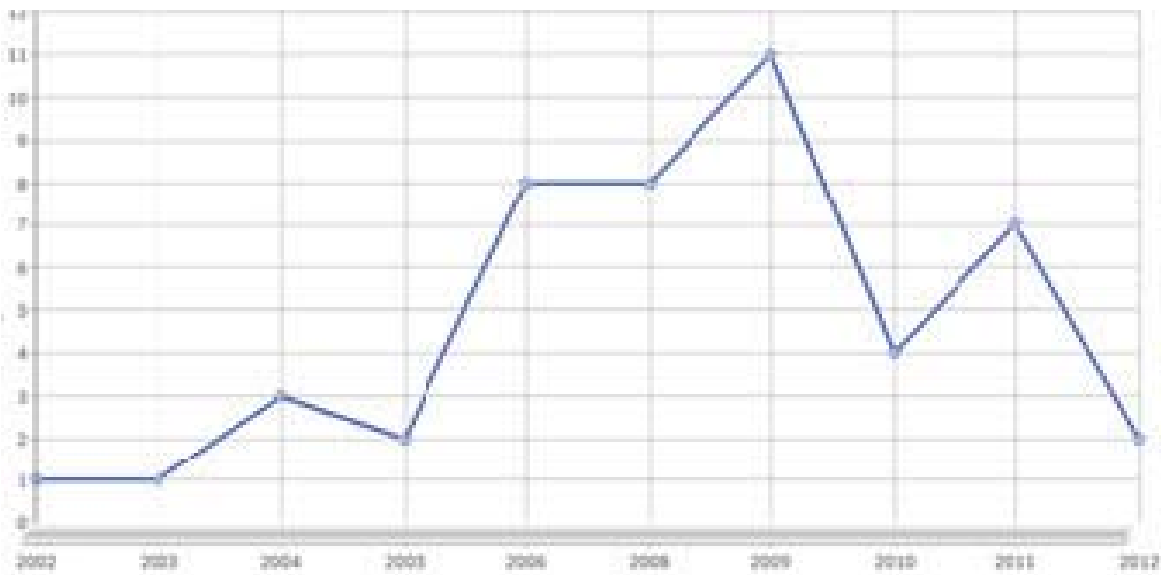

Figure 1. The number of accredited private universities in Albania

3. The increase in number of private universities was another characteristic of the period. Due to the incapability of the public universities to respond to the increasing demand for education, private sector eventually exploited the opportunity by creating private universities. This activity is reflected in Figure 2, below. During 2003-2012 a further demand for entry in universities is observed. Compared to the previous time period the number of enrolled students significantly increased as illustrated in Figure 3. 


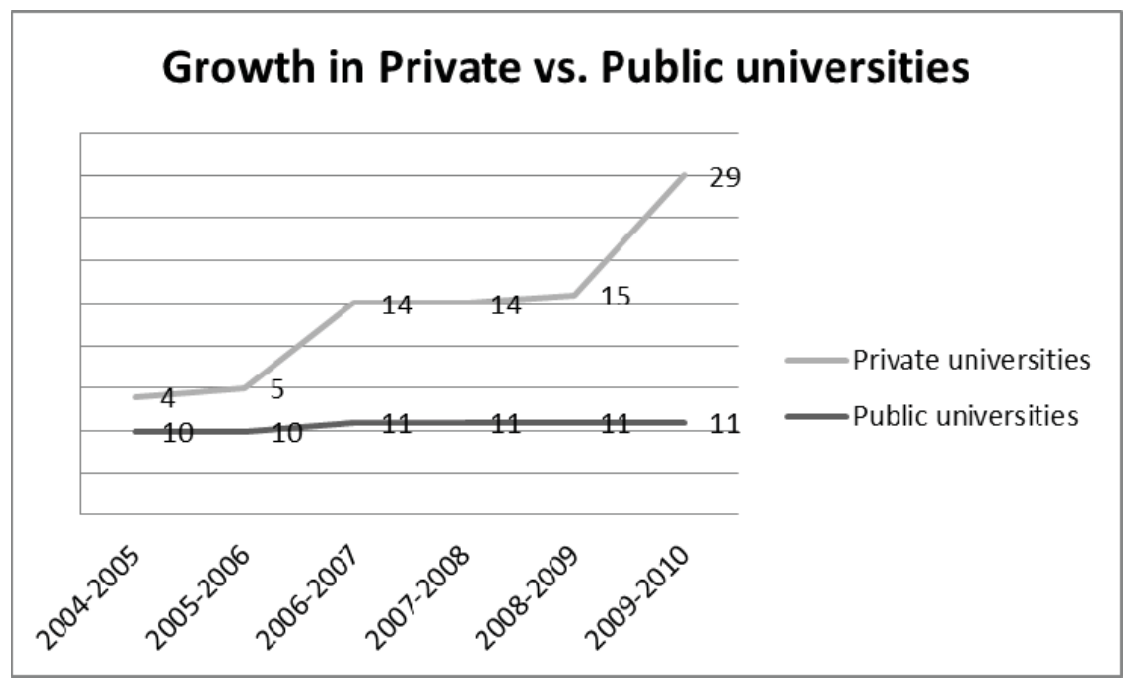

Figure 2. Growth in public vs. private universities

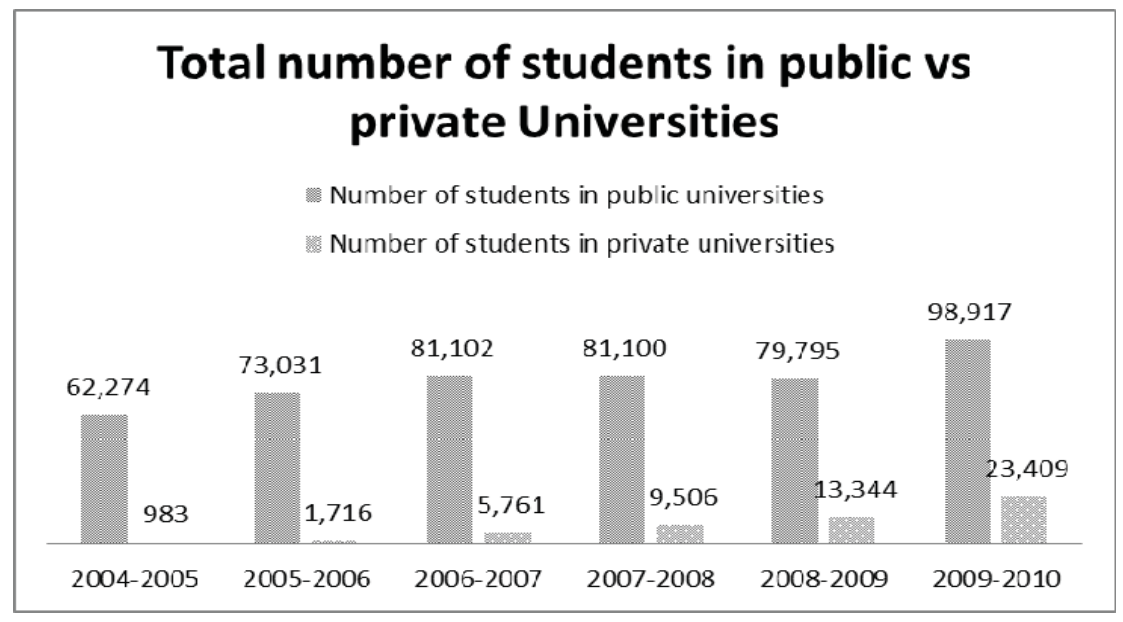

Figure 3. Total number of students in public vs. private universities

According to the Head of Ministry of Science and Education during 2011-2012 in public universities of Albania were enrolled 55000 full-time and part-time students in Bachelor, Master and PhD programs. This number of students is equal to the number of students enrolled in 2004 in both public and private universities. 9\% of this number was coming from students enrolled in private universities (Tafaj, 2011). This is a significant element evidencing the huge increase in students over the years. The majority of students pursued Bachelor degrees. There were 15500 Master students, while $\mathrm{PhD}$ candidates made up the rest of the overall number. Despite students enrolled in Albania, there is a big number of Albanian students studying abroad. Regarding the small population of Albania and the large number of students, the rate of students per inhabitants is alike any other Western European country.

\section{Findings and Discussion}

Bologna reform was not easy, it had its ups and downs. It was affected by external factors such as: political and 
economical developments, as well as internal factors like: the inclusion of a voting system for the heads of academic institutions, imposing new criteria to get scientific qualification and new criteria based on which students would get accepted.

\subsection{Problems with course curricula}

For the Albanian academic system to fully embrace the Bologna Process, several duties had to be fulfilled. The first one was to redesign the course curricula for Bachelor, Masters and PhD programs (SOROS, 2004). Curricula needed improvement to exclude all political content. This was a phenomenon not only reflected in Albania but in other ex socialist countries as well (Rozsnyai, 2003). The majority of curricula were redesigned based on the Albanian academic tradition as well as the experience gained from Western European countries. However, they still lack in reflecting the latest scientific developments and in fulfilling every need imposed by the job market. The whole redesigning process requires a periodic monitoring which can make sure there is continuance from one academic stage to the other. An evident problem that exists today regarding curricula is their vast diversification which can even go beyond the capacity of universities. Sanctioning these expansions cannot only be made by taking administrative measures because academic senates are the responsible bodies which decide on the issue. There is a tendency in both private and public universities to expand the number of taught programs. Career advising offices within universities are almost non-existent; there are not enough market researches to identify professions currently in need. However, recently there have been attempts to identify the areas of future economic and political potential on which students and universities should focus. Due to Albania's geographical position, natural resources and economic level, there is a need for professions regarding: Albanology, Energy, Mineral extracting industry, IT, Archeology, Tourism, Environmental sciences, etc (Tafaj, 2011). Universities should focus more on developing programs on these scientific areas of study.

\subsection{Dissproportionate number of taught programmes}

Currently there is a disproportionate number of taught programs in the 3 cycles of study, Bachelor, Masters and PhD respectively. The higher education has currently 556 programs of study in all 3 cycles. Out of this, 264 partain to Bachelor degrees (Musai, 2012). This number is very high compred to the number of enrolled students, the small population size of Albania and the static job market. The logical spread of programmes would be to have less in Bachelor and more professional specializations in Masters and PhD. This is because students who apply for a Bachelor program cannot have specific knowledge of the programe they are applying for because is the earlies stage of their studies. At Masters level students are specifically focused in their area of interest and more programmes should be availbale to chose from.

There is currently an issue in having unification among programs of study during the 3 cycles. They should follow a harmonic and logical flow. The large number of programes offered decreases the quality and there are not enough qualified lecturers to teach each offered programe. Despite the fact that new academic staff hired has graduated in foreign prestigious universities and government attempts like "Brain Gain programe" and "Excelence Fund", there are still needs for highly qualified academics. However there have been improvements, in 201170 member of existing academics were backed by the government for PhD studies in top world universities.

\subsection{Inapproriate valuation of academic staff}

It is important to state that the evaluation of academic staff was made by external experts. However it was not fully and appropriately conducted. The experts have only considered: the teaching quality, student supervision, publications in scientific journals, participation in conferences. No attention was put to the real scientific impact that works published by these academics had on the university as well as how appropriate the referencing in their articles was. External experts did not consider the amount of income generated from applying these scientific findings into real work areas and how much foreign recognition did the university get from these scientific works. As Savickiene (2005) puts is it "the author suggests that assessment should be more based on the analysis of what and how has been improved, reviewing not only opportunities for studies but emphasizing what has been done to improve those opportunities" 


\section{Conclusions}

For the Albanian academic staff to be able to keep up with academic standards of their cohorts in developed European countries, they should be more involved in EU programs such as Erasmus Mundus, Marie Curie, Jean Monnet International etc (Tafaj, 2011).

To provide quality, the evaluation process of students should be objective and fair because their grades would have an impact on their future career. To be able to identify any drawbacks of the system, students' responses should be taken into account. Till date there are no data regarding alumni employment rates and universities do not maintain further connections with students after they graduate. The general prevailing opinion is that graduates from the public universities of Tirana are the most qualified and they have an advantage in the job market. For now this is the only indicator of quality in public universities. However, there should be a close cooperation between academics and human resource managers to fulfill market needs for professionals (Kohont, Bergoc, 2010).

The heads of higher education institutions are responsible for ensuring that students have an adequate infrastructure and high quality services which support each taught programe. This means that students should be made available facilities such as: library resources, computer laboratories and other kinds of laboratories. Despite these, students should have human resource facilities that could help them like: supervisors, career advisors, consulting bodies, etc.

The supporting staff of every university plays a big role too. There should be a qualified and fully functioning record 'office, departmental office, assigned program office, etc., for which current students often complain. Heads of universities should continuously monitor and asses the functionality of these offices. As Spendlove (2007, p.2) states " The research shows that university leadership is fundamentally different from leadership in other contexts, and demands additional competencies."An issue that currently prevents this is the lack of financial autonomy of universities and the limited funds available to them. This is easier to be carried forward in private universities.

From the above mentioned facts and figures it is obvious that there exist many problems in the Albanian system of higher education. This was mainly due to the liberalization process which changed things and the closed minded communist mentality used to judge this whole process. Liberalization brought with itself a new business concept that involved education and had essential differences from every other business developed so far. Education has nothing to do with business, it is an investment for knowledge, technology, science, infrastructure and for the future. Investing in these areas increases the competition between public and private universities as well as the interest of society to fund these institutions.

Overcoming these obstacles and succeeding the long challenge with quality assurance would make it possible for the Albanian education system to integrate into the European education system. This article only considered the main factors affecting quality but there are also sudvisions to focus on. This limitations can serve as an area of interest for future potential authors concerned on the quality issues in higher education.

\section{Acknowledgements}

I am thankful to the Alban Public Accreditation Agency for Higher Education (APAAL) for which I have previously worked and that gave me the access to some of the data included in this article.

\section{References}

Agjencia Publike e Akreditimit te Arsimit te Larte (APAAL) (2007). Standarde dhe udhezime per sigurimin e cilesise ne hapesiren Europiane te arsimit te larte.

Agjensia Publike e Akreditimit te Arsimit te Larte (APAAL) (n.d.). Lista e Institucioneve private. Retrieved from: http://www.aaal.edu.al/index.php?option=com_content\&view=article\&id=384\&ltemid=256\&lang=sq

Frank, A., Kurth, D. and Mironowicz, I. (2012). Accreditation and quality assurance for professional degree programmes: comparing approaches in three European countries. Quality in Higher Education, 18 (1), p. 75-95.

Kohont, A. and Bergoc, N. (2010). On the Way into the Bologna Reform--A Consideration of the Quality and the Role of Human Resource Management in Higher Education System. Quality of Higher Education, 7, 12-36.

Mishra, S. (2007). Quality assurance in higher education; An intorduction. Karnatak: India.

Musai, B. (2012). Procesi I Bolonjes nga Retorika ne Praktike. Gazeta Panorama. 
Pratasavitskaya, H and Stensaker, B. (2012). Quality Management in Higher Education: Towards a Better Understanding of an Emerging Field. Quality in Higher Education, 16 (1), p.37-50.

Savickiene, I. (2005). Parameteres of Higher Education Quality Assesment System at Universities. Quality of Higher Education, 2, $72-83$.

Rozsnyai, C. (2003). Quality Assurance Before and After 'Bologna' in the Central and Eastern Region of the European Higher Education Area with a Focus on Hungary, the Czech Republic and Poland. European Journal of Education, 38 (3) p.271-284.

SOROS (2004). Bolonja ne 7-te hapa. Mesonjetorja, Tirane: Albania.

Spendlove, M. (2007). Competencies for effective leadership in higher education. International Journal of Educational Management, 21 (5).

Tafaj, M. (2011). Rritja e cilesise nuk mund te arrihet pa nje internacionalizim te shpejte te universiteteve. Speech held at Fan Noli University, Korce me 10 Tetor 2011. Retrieved 15/10/2012 from Albanian Ministry of Science and Education website: http://mash.gov.al/

Tafaj, M. (2011). Strategjia e Bashkimit Europian /20 per kerkimin, inovacionin dhe trajnimin. Conference organized by Ministry of Science and Education, and Council of Europe.

Tsinidou, M., Gerogiannis, V. and Fitsilis, P. (2010). Evaluation of the factors that determine quality in higher education: an empirical study. Quality Assurance in Education, 18 (3), 227-244.

Woodard, C. (2005). Albania's Universities, Long Hobbled, Struggle to Rise. Chronicle of Higher Education, 52, (30).

Yarmohammadin, H.M., Mozaffary, M., and Esfahani, S. Sekineh. (2011). Evaluation of quality of education in higher education based on Academic Quality Improvement Program (AQIP) Model. Procedia Social and Behavioral Sciences 15, 2917-2922.

Zgaga, P. (2009). The Bologna Process and its role for transition countries. Revista de la Educación Superior 38 (2) No.150. 
